\title{
APLICAÇÃO DE TÉCNICAS DE OSM PARA MELHORIA DO DESEMPENHO ORGANIZACIONAL: ESTUDO DE CASO EM UMA EMPRESA DE DELIVERY DE HAMBÚRGUER
}

Everton Ramos dos Santos (UFPE/CAA) evertonramosep@gmail.com Dara Alice da Silva Nunes (UFPE/CAA) daraasnunes@ outlook.com Magdiel Lopes Pereira Neto (UFPE/CAA) magdielneto@gmail.com Edinalva Nogueira de Carvalho (UFPE/CAA) edinalvanogueiraufpe@gmail.com

\section{Resumo}

A área de Organização, sistemas e métodos (OSM) tem grande importância para as organizações, uma vez que, apresenta técnicas para gerenciar de forma eficaz seu ambiente organizacional. Desta forma, o presente trabalho tem como objetivo analisar e aplicar as técnicas associadas ao conceito de OSM em uma Hamburgueria, localizada no Agreste Pernambucano, visando através do estudo dos processos e do layout, reduzir perdas e atender às necessidades e expectativas dos consumidores. Para o levantamento das informações foram aplicados, questionário e entrevista com o gestor da organização, bem como observação in loco. As ferramentas utilizadas para diagnosticar as causas dos problemas foram: Diagrama de Causa e Efeito e o Gráfico de Pareto. Como resultado, foi identificado que o maior entrave que a organização estava enfrentando era a não conformidade dos produtos em relação aos pedidos, uma vez que, estava associada principalmente à problemas de layout e processos. Neste sentido, foram propostas melhorias no mapeamento dos processos com o apoio do fluxograma e de um novo layout que auxiliasse nos fluxos de pessoas, equipamentos e informações.

Palavras-Chaves: Organização, Sistema e Métodos. Estrutura organizacional. Organização do Trabalho. Racionalização do trabalho.

\section{Introdução}

Inseridas num ambiente altamente competitivo, as empresas têm investido em estratégias que reduzam suas perdas e aumentem seus índices de produtividade, permitindo processos otimizados e consequentemente vantagens competitivas diante do mercado. Com isso, atuar em setores produtivos em ascensão requer organizações cada vez mais preparadas, em termos de processos, produtos e serviços prestados. 
O setor alimentício tem atingido patamares mais elevados com o passar dos anos e suas derivações seguem esse crescimento, como pode-se perceber pela procura por opções de alimentos rápidos e práticos, tido como o fast food. Além disso, devido a rotina acelerada, os consumidores têm desenvolvido uma demanda cada vez maior por serviços de delivery, que traz como vantagens a comodidade, segurança, versatilidade de horários e economia (GERMANO; GERMANO, 2013).

Diante disso, a exigência cada vez mais crescente no atendimento da satisfação dos consumidores, faz com que as empresas invistam cada vez mais na melhoria dos seus processos e na qualidade dos seus produtos. E com isso, se torna primordial o estudo de Organização, Sistemas e Métodos (OSM). OSM é a junção das funções de Organização e Planejamento, que atua na construção da estrutura de recursos e de processos, na determinação dos planos, e principalmente na definição dos procedimentos, rotina e métodos (ROCHA, 1998).

Em virtude disso, o estudo em questão tem como objetivo analisar e aplicar as técnicas associadas ao conceito de OSM em uma Hamburgueria, localizada no Agreste Pernambucano, visando melhorar os processos por meio de técnicas que atuem para redução de tempo, esforço e custo, com o intuito de atender às necessidades e expectativas dos consumidores, garantindo destaque no mercado.

Assim, o trabalho apresenta um estudo bibliográfico a respeito de OSM e as técnicas associadas como: arranjo físico(layout) e gestão de processos e em seguida descreve a metodologia que se seguiu. Posteriormente, se trata da situação atual da empresa, e quais são as propostas de melhorias, tidas a partir das análises embasadas nos conceitos de OSM e na sequência, quais as considerações que se foram possíveis a partir do estudo realizado na empresa.

\section{Referencial teórico}

\subsection{Organização, sistemas e métodos (OSM)}

Segundo Cury (2012) Organização, Sistemas e Métodos (OSM) é definido como uma das funções da administração responsáveis pela modelagem da empresa, sendo responsável em aplicar melhorias, acompanhar processo, dentre outros. Sendo assim, OSM utiliza técnicas e métodos para alcançar os objetivos organizacionais.

Neste sentido, Souza et al. (2015) ressalta que OSM tem como objetivo aperfeiçoar processos, trazendo aperfeiçoamento contínuo, redução de custos e aumento da produtividade. 
Corroborando com o mesmo pensamento, Pizza (2012) enfatiza que OSM é uma área da administração que contempla um conjunto de técnicas e tem como principal objetivo tornar o funcionamento das organizações eficazes.

Segundo Cruz (2002) OSM é o estudo das organizações por meio da análise de cada uma das atividades, a fim de criar procedimentos que venham interligá-las de forma sistêmica. Neste sentido, Rocha (1998) enfatiza que OSM é uma função mista de Organização e Planejamento, logo define procedimentos e métodos, bem como determina os planos nas organizações. Cury (2000) enfatiza que a função de OSM tem como objetivo final a renovação da organização, por meio da sinergia entre a empresa e as demandas de seu ambiente.

Para Oliveira et al (2011) a área de OSM tem várias finalidades, onde se podem destacar: padronização de procedimentos e ferramentas; eliminação de atividades desnecessárias; otimização de processos e recursos; redução de custos; racionalização na distribuição de tarefas; elaboração de manuais e formulários; otimização do layout, dentre outras. A área de OSM vem aumentando sua atuação entre as organizações visando a reorganização dos métodos e propondo ajustes para mantê-las com efetividade e eficácia (SOUZA et al., 2015).

\subsection{Arranjo físico (Layout)}

Atualmente, as empresas a fim de ser manter competitivas no mercado que atua, devem buscar alternativas que tornem seus recursos mais eficazes, e uma dessas alternativas é realizar um bom estudo de arranjo físico. Uma vez que, Assunpção e Jacobs (2019) Consideram o estudo do arranjo físico de grande importância para que as indústrias operem de maneira eficiente e eficaz, logo o arranjo físico adequado, permite a otimização do fluxo de pessoas, materiais e equipamentos no âmbito do sistema, o que para Gaither e Frazier (2002) minimiza os custos de processamento e desperdícios de tempo e materiais.

Em consonância, Araújo (2009) enfatiza que os recursos devem ser estabelecidos a partir de estudos planejados relacionados com a distribuição de mesas, estações de trabalho, móveis e equipamentos. Do ponto de vista de Slack et al. (2009), o arranjo físico de uma operação ou processo dispõe sobre como seus recursos transformadores são posicionados uns em relação aos outros e como as várias tarefas da operação serão alocadas a esses recursos transformadores.

Segundo Slack et al. (2009), os arranjos físicos são classificados em: 
a) Arranjo físico posicional ou posição fixa: neste tipo de arranjo físico os recursos transformados permanecem de forma fixa, e os recursos transformadores são movimentados no processo de fabricação na medida do necessário. Ou seja, quem sobre o processamento fica estacionário. Exemplo: construção de rodovia, navio, dentre outros;

b) Arranjo físico funcional ou por processo: neste tipo de arranjo permite que os recursos ou processos semelhantes permaneçam na mesma área de atuação, ou seja, são localizados juntos um do outro. Exemplo: supermercado, hospital, entre outros;

c) Arranjo físico celular: é aquele em que os recursos transformados, entrando na operação, são pré-selecionados para movimentar-se para uma parte específica da operação (ou célula) na qual todos os recursos transformadores necessários a atender às suas necessidades imediatas de processamento se encontram, ou seja, as máquinas são agrupadas para atender parcial ou completamente às demandas de uma determinada família de produtos, os quais necessitam dos mesmos recursos. Exemplo: Maternidade em um hospital, dentre outros.

d) Arranjo físico por produto: os recursos em transformação seguem um fluxo ao longo da linha de processo. Os operadores, máquinas ou equipamentos devem estar alocados na sequência das operações. Exemplo: montagem de automóveis.

Vale ressaltar a importância de identificar qual o melhor tipo de arranjo físico se adequa na organização. Logo, uma decisão correta do arranjo físico evita resultados indesejados, como altos custos, perdas na produção e lead times elevado (SLACK et al., 2009). Além de envolver prioridades estratégicas para a competitividade, qualidade e capacidade produtiva dos processos (KRAJEWSKI; RITZMAN; MALHOTRA, 2009). Sendo que, é enfatizado por Araújo (2009), que as organizações estão na busca pelo melhor funcionamento de todos os processos, visando aumentar o valor de percepção para o cliente. Desta forma, a próxima seção trata-se sobre alguns conceitos chaves para a gestão de processos.

\subsection{Gestão de processos}

De acordo com Baldam et al. (2014), um processo é uma atividade ou conjunto de atividades que tem input, desenvolve-se e no output entrega um valor específico ao cliente. Corroborando deste pensamento Brocke e Rosemann (2013) enfatizam que o processo está ligado ao fornecimento de bens e/ou serviços aos clientes, e que não há produto e/ou serviço 
oferecido por uma empresa sem um processo (GONÇALVES, 2000). Tornando assim, primordial conhecer o fluxo de trabalho para o desenvolvimento de produtos e serviços.

Para Paim et al (2009) os processos estão relacionados com o gerenciamento da organização, pois busca promover a realização das atividades e utilização dos recursos da forma mais adequada possível. Desta forma, Paim et al. (2009) ressaltam que gerenciar uma organização por uma abordagem de processos torna possível a coordenação do trabalho promovendo um maior nível de aprendizado e melhoria contínua das operações.

Association of Business Process Management Professionals - ABPMP (2009) classificam os processos em:

a) Processo primário: neste processo, as atividades são contempladas como essenciais por representar a essência de finalização de um processo específico;

b) Processo de suporte: está vinculada ao valor que este tipo de processo repassará a um outro processo e não diretamente ao cliente, ou seja, são os processos que suportam os processos primários, dando-lhes apoio para que possam existir;

c) Processo gerencial: assegura que a organização operacionalize suas funções em concordância com os seus objetivos e metas de desempenho. Eles coordenam as atividades dos processos primários e de suporte, buscando a eficácia e eficiência da empresa.

A gestão de processos é definida como sendo uma abordagem disciplinar para identificar, desenhar, executar, documentar, medir, monitorar, controlar e melhorar os processos de negócios, para alcançar os objetivos estratégicos da organização. A gestão de processos visa gerenciar os processos de negócios de ponta a ponta, onde envolve o ciclo completo de planejar, fazer, estudar e agir (ABPMP, 2009).

Logo Albuquerque e Rocha (2007) enfatizam que para o início de qualquer esforço para melhoria de resultados é necessário saber onde a organização estar e aonde quer chegar. Estes dois questionamentos são essenciais para que as organizações possam desenvolver meios para alcançar os resultados pretendidos.

\section{Metodologia}

Para este trabalho, realizou-se um estudo de caso em uma lanchonete delivery situada na cidade de Bezerros - PE, e o desenvolvimento deste, se deu conforme apresentado na figura 1. 
Figura 1- Fluxograma das etapas do trabalho

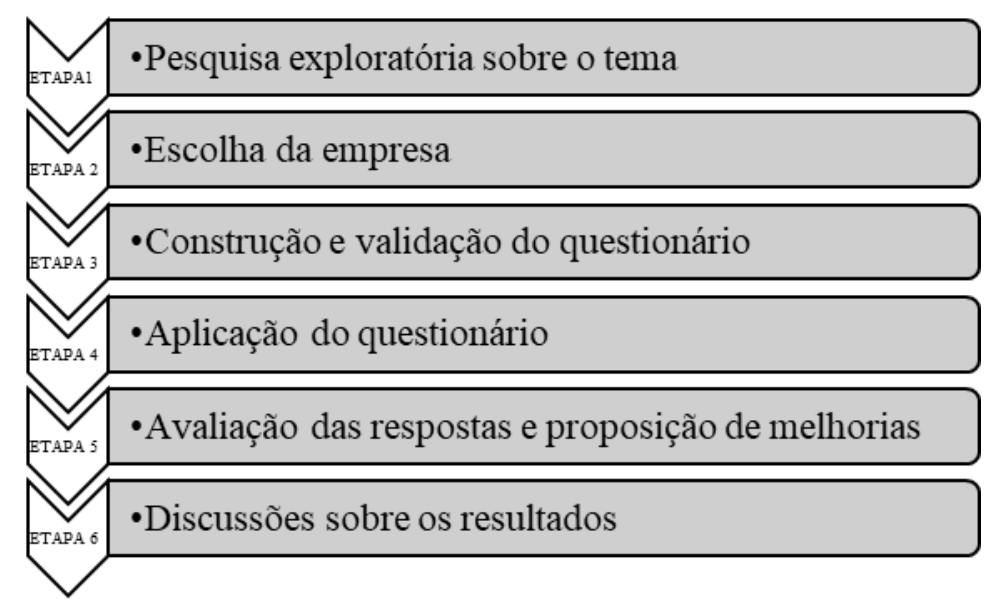

Fonte: Os autores (2020)

Inicialmente, na etapa 1, realizou-se uma pesquisa exploratória sobre o tema, abordando conceitos ligados à OSM, Gestão de processos e Arranjo físico (layout). Em seguida (etapa 2), escolheu-se a empresa que seria o objeto de estudo, levando em consideração a proximidade do espaço físico em relação aos autores do trabalho, facilidade de comunicação entre as partes e o interesse em melhorar os processos por parte da gerência. A empresa, neste caso, foi uma lanchonete delivery que dispõe de um portfólio de produtos diferenciado e que tem se destacado na cidade. A etapa 3 consistiu na construção e validação de um questionário que pudesse nortear a conversa com o gestor da empresa a fim de identificar e propor melhorias para os processos e o arranjo físico atual. O questionário considerou as seguintes perguntas:

a) Quais as maiores dificuldades encontradas na produção?

b) O que dificulta para que um funcionário realize o trabalho de outro funcionário?

c) O que poderia ser feito para melhorar os processos da empresa?

d) O que afeta a entrega dos produtos?

e) O que os clientes dizem a respeito dos produtos? Estão conforme o esperado?

f) O que é feito para atender demandas "urgentes"?

As etapas 4 e 5 consistiram na aplicação do questionário por meio de uma entrevista semiestruturada com o gestor. Ao decorrer da entrevista, algumas dúvidas surgiram e foram esclarecidas imediatamente por ele. Além disso, a observação ao local de trabalho trouxe outras contribuições, antes não identificadas ao decorrer da conversa. Portanto, a partir da identificação das possibilidades de melhoria, algumas propostas foram elaboradas e apresentadas ao gestor da empresa. Essas propostas foram desenvolvidas com o auxílio de 
ferramentas da qualidade, bem como com conceitos de gestão, estratégia e organização do trabalho, e foram medidas por meio de indicadores de desempenho.

Por fim, foi realizada uma discussão sobre as contribuições que o trabalho proporcionou para a organização em geral (etapa 6), percebendo as vantagens competitivas que se obtém com o investimento de melhorias no ambiente e na realização do trabalho.

\section{Resultados}

Após discutido sobre como a OSM pode contribuir para solucionar os problemas encontrados, algumas melhorias foram desenvolvidas e submetidas à gestão da empresa. Em virtude disso, se faz necessário, apresentar inicialmente um panorama dos processos atuais da Lanchonete.

\subsection{A empresa}

A empresa em estudo, é uma Lanchonete Delivery de Hambúrgueres, atuante no segmento há 5 anos, na cidade de Bezerros, no Agreste Pernambucano. Destacando-se no ramo de fabricação de bens alimentícios e prestação de serviços. Possui em seu quadro de colaboradores: 2 Entregadores, 2 Cozinheiras, 1 Atendente de Caixa e 1 Gerente. Em dias de maior demanda, se faz necessário a contratação temporária de 1 Cozinheira, 1 Auxiliar de cozinha e 1 Entregador. O seu organograma é constituído da seguinte forma, como é apresentado na Figura 2.

Figura 2- Organograma da empresa

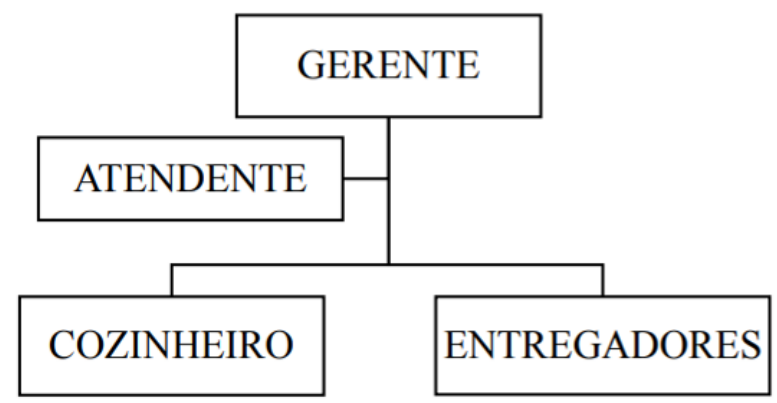

Fonte: Os autores (2020)

Entendendo que atua num segmento altamente competitivo, a empresa adota estratégias que permitem seu destaque, como o fato de apresentar uma diversidade de hambúrgueres em seu portfólio, produzir os pães e as carnes de hambúrgueres artesanalmente, e o serviço de entrega gratuito. Com isso, a empresa garante sabor e atendimento personalizado e a partir disso, conquista vantagens competitivas. 
Os produtos oferecidos, tem como público alvo jovens e adultos, com faixa etária entre 15 e 35 anos, da classe A e B, e usuários das Redes Sociais. Tais itens são agregados em 4 categorias: hambúrgueres, sanduíches, batata frita e bebidas. No entanto, vale ressaltar, que os hambúrgueres são os produtos-chave da organização.

Seu processo produtivo é constituído em: Atendimento das necessidades que cada cliente faz com relação ao seu pedido (através das Redes Sociais ou ligações telefônicas), Fabricação e Confecção do Hambúrguer, e Entrega ao cliente final, na sua localidade. Para que esse processo seja possível, a empresa dispõe de um espaço físico simples, sendo formado apenas pela sala de atendimento de pedidos, cozinha, setor de embalagem e depósito. Tendo em vista que a empresa atua apenas no atendimento delivery, não se faz necessário um espaço destinado para a recepção dos clientes. Para uma melhor visualização, na Figura 3 tem-se o layout atual da organização.

Figura 3 - Layout atual da organização

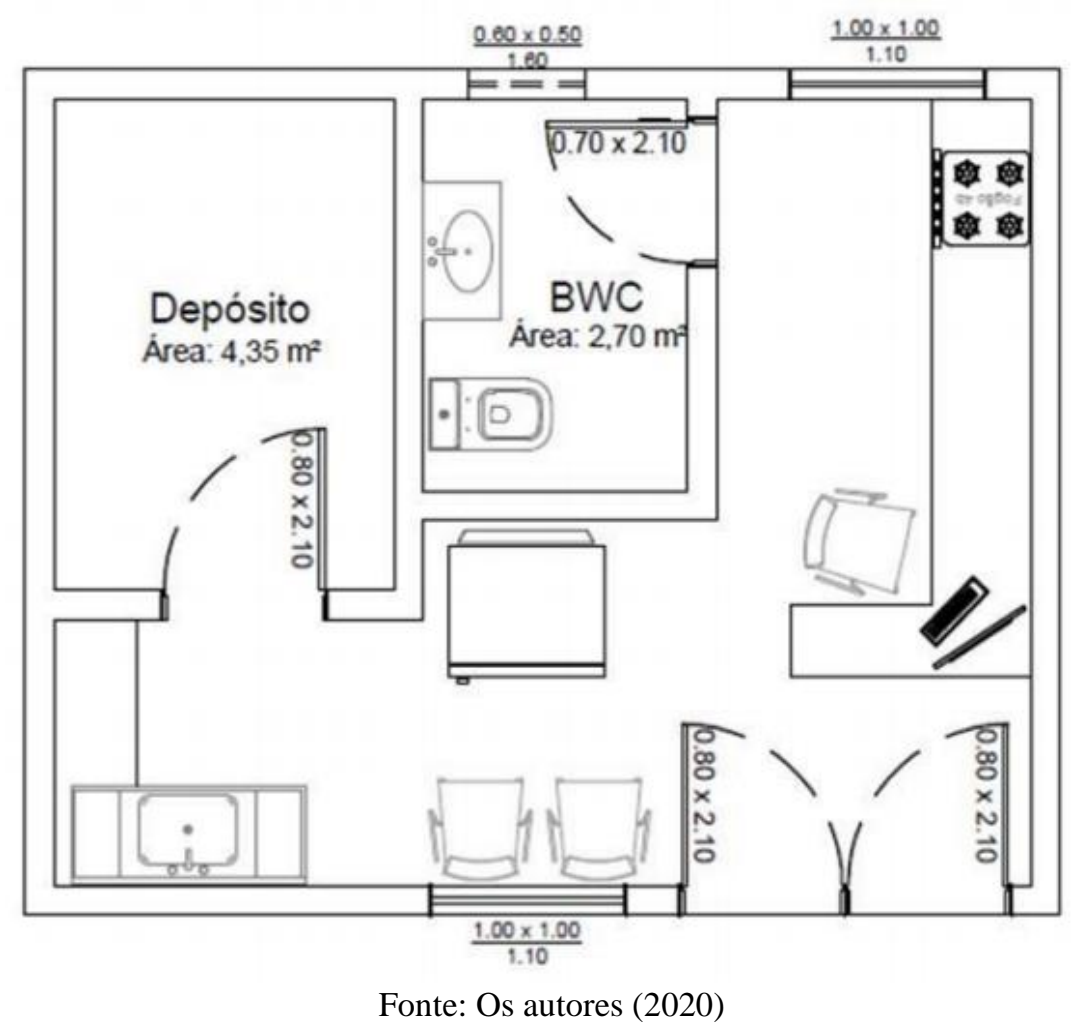

\subsection{Propostas de Melhoria}

Tendo em vista as informações coletadas durante a aplicação do questionário, foi possível entender quais as maiores reclamações referentes ao processo, na perspectiva do cliente. 
Dessa forma, tem-se um Diagrama de Pareto sinalizando o problema com maior ocorrência (Figura 4).

Figura 4 - Diagrama de Pareto referente aos problemas do Delivery

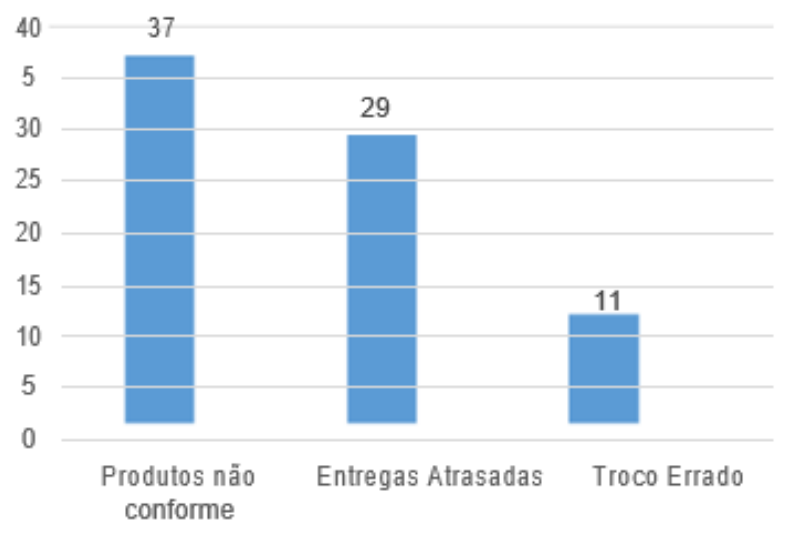

Fonte: Os autores (2020).

Sendo:

- Produtos não conformes: acontece quando o produto chega ao consumidor com alguma não conformidade, levando em consideração o pedido que foi realizado anteriormente, como por exemplo, a presença ou ausência de salada quando solicitado.

- Troco Errado: refere-se ao fato de haver uma não conformidade relacionada à quantia repassada ao cliente, causando transtornos para o mesmo e para a empresa.

- Entregas Atrasadas: refere-se à extrapolação do tempo previsto para a entrega do produto. Vale ressaltar que, entregas atrasadas prejudicam a imagem da empresa.

Com base nisso, foi construído um Diagrama de Causa e Efeito, que possibilitou identificar as principais causas do problema "Produtos não Conformes" (Figura 5). E a partir disso, algumas melhorias foram traçadas com o objetivo de atuar nestas. 
Figura 5: Diagrama Causa e Efeito - Produtos não Conformes

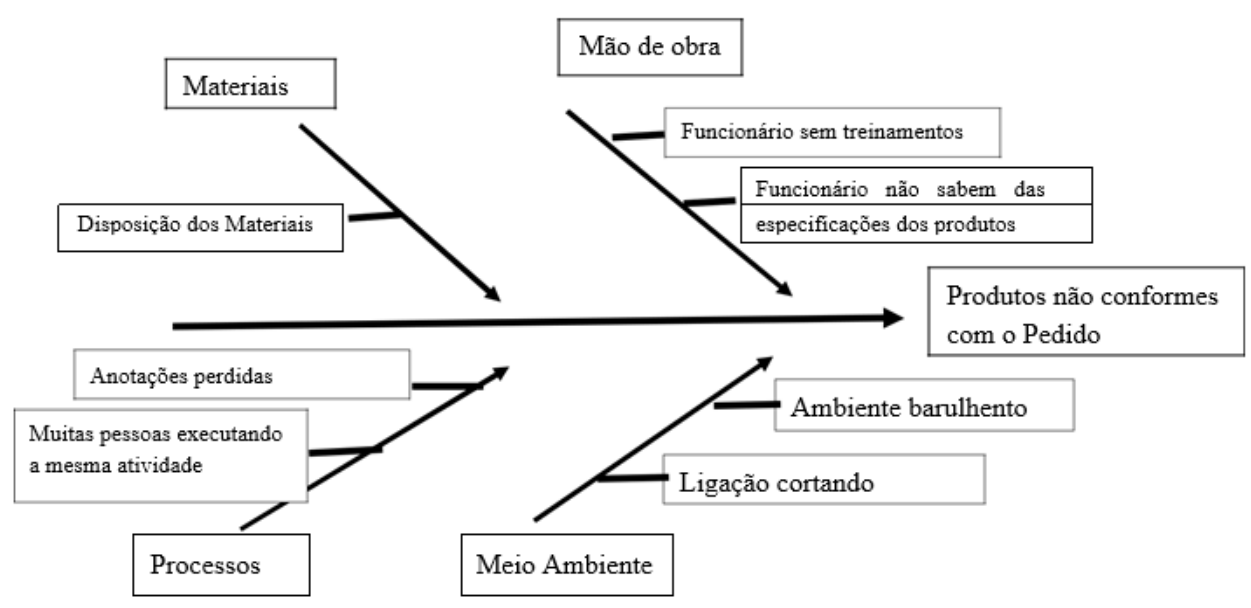

Fonte: Os autores (2020).

Portanto, a partir da análise do Diagrama de causa e efeito, foi identificado que dentre as maiores causas para que os produtos não estejam conformes com os pedidos, as principais, estão distribuídas em algumas categorias: materiais, mão de obra, processos e meio ambiente; e a elas, estão associados problemas como anotações perdidas, falhas na comunicação, funcionários sem treinamentos, entre outros. Então, o próximo passo consistiu na proposição de melhorias que atacassem estas categorias, mais precisamente os processos e o layout atual da empresa. Com isso, as pessoas que realizam as atividades estarão mais conscientes dos caminhos que precisam seguir e de como realizar suas atribuições.

A primeira parte da proposição das melhorias foi entender o processo produtivo da empresa, e a partir disso, construir o mapeamento do mesmo, utilizando o fluxograma como apoio. Dessa forma, foi possível estabelecer um padrão em termos de processo produtivo, produto e prestação de serviço. Outro benefício associado, é o fato de que, como a empresa atua com variação no seu quadro de colaboradores de acordo com a demanda, todos precisam estar treinados a executar as atividades da mesma maneira, ou seja, seguindo um fluxo padrão.

Dessa forma, tem-se na Figura 6, o fluxo do processo de Atendimento e Processamento dos Pedidos. 
Figura 6- Fluxograma de atendimento

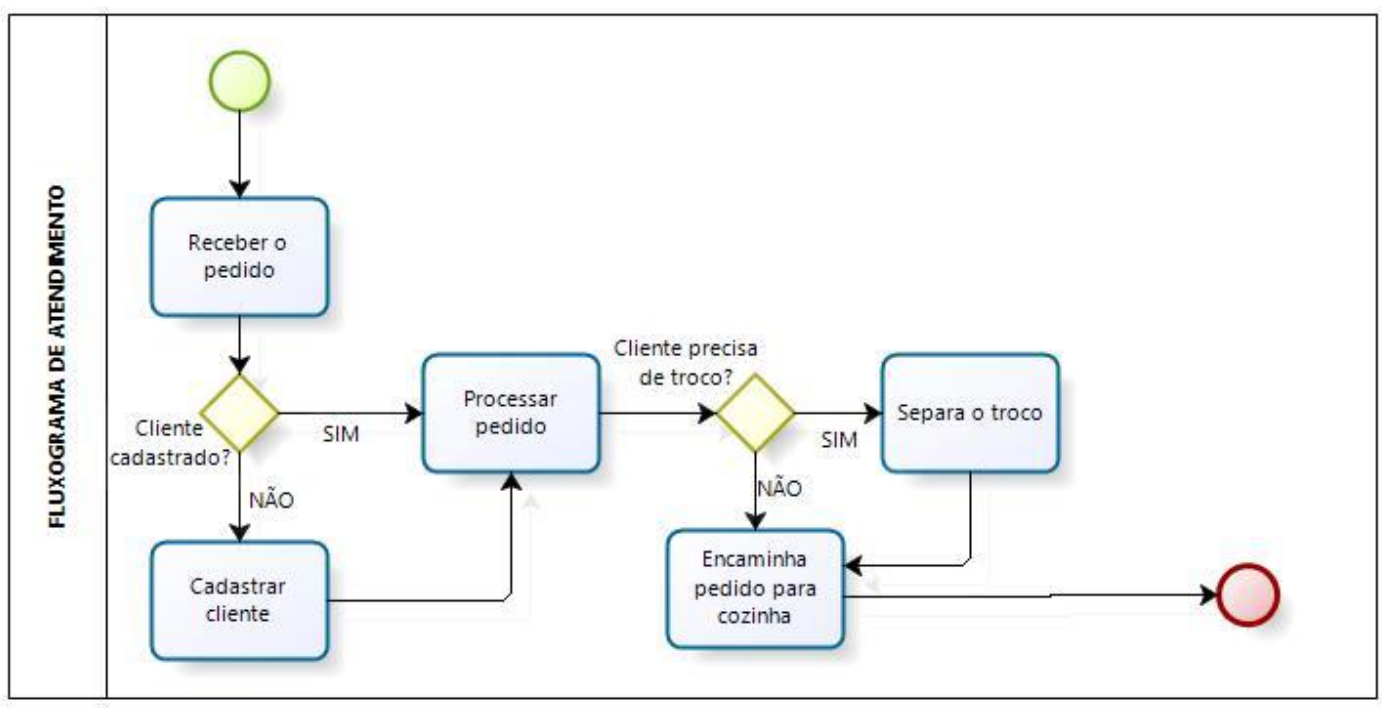

Fonte: Os autores (2020)

No que se refere ao processo de Entrega dos Produtos, tem-se o fluxo como apresentado na Figura 7.

Figura 7- Fluxograma de entrega dos produtos

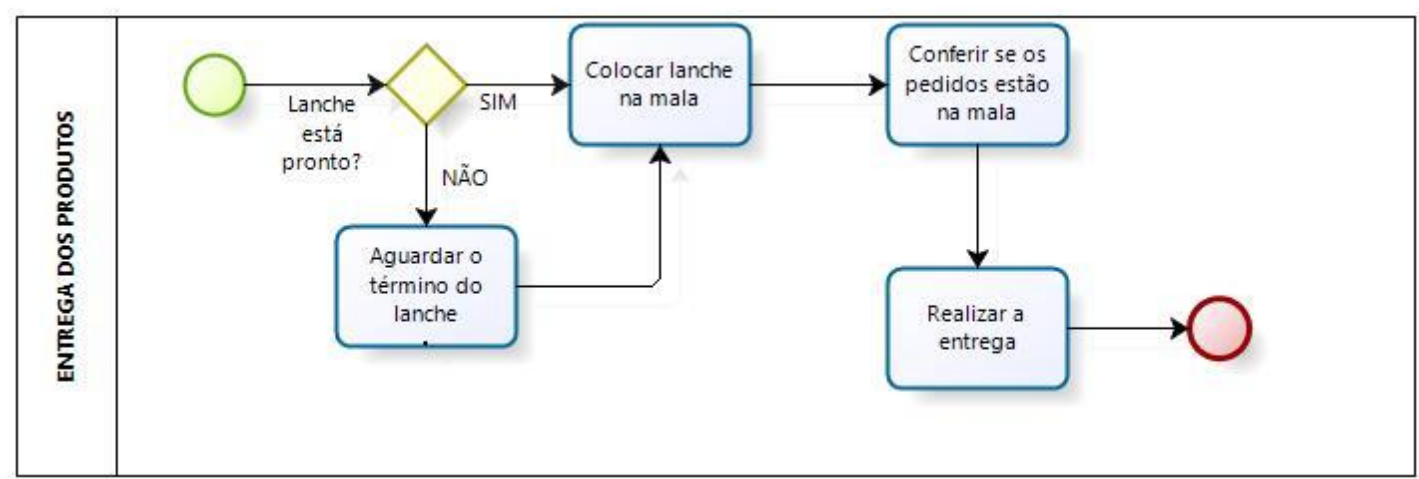

Fonte: Os autores (2020)

Tendo em vista que um bom fluxo requer um bom layout, se fez necessário reestruturar a disposição dos setores, seus equipamentos e utensílios, permitindo a execução eficiente das atividades e um melhor aproveitamento do ambiente. Dessa forma, tem-se o novo layout (Figura 8). 
Figura 8- Proposta do novo layout

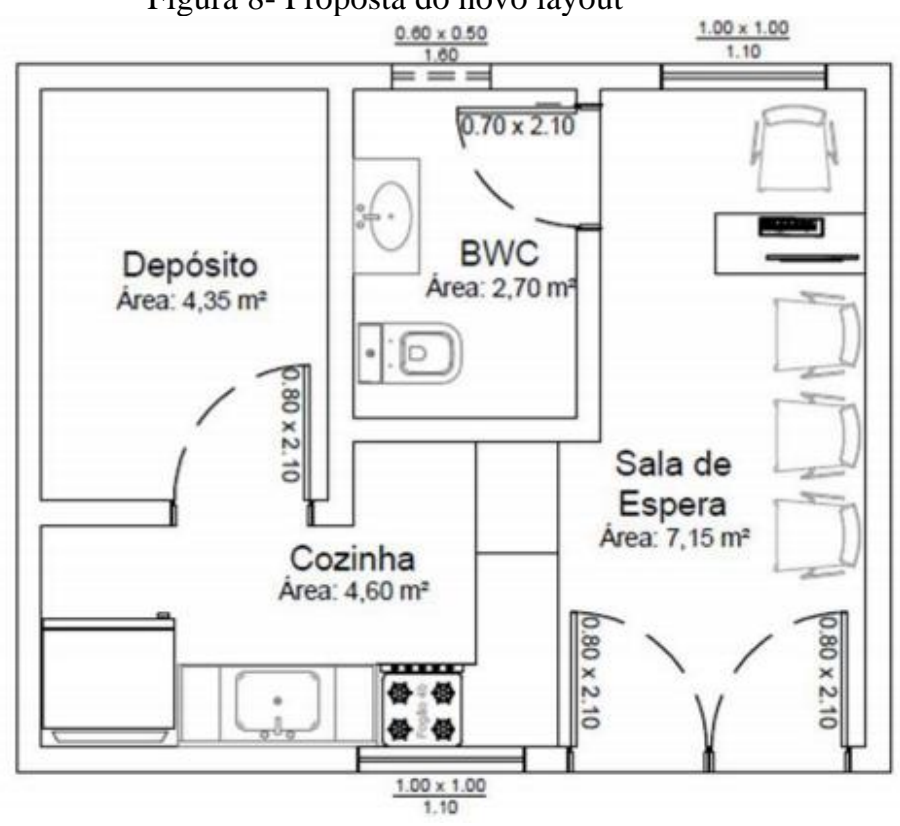

Fonte: Os autores (2020)

Com a implementação do novo layout é possível reorganizar o ambiente de acordo com o fluxo produtivo, o que reduz perdas relacionadas a transporte, manuseio de materiais e espera, tidas como atividades que não geram valor agregado ao produto. Além disso, outros benefícios estão relacionados ao posicionamento de cada colaborador, permitindo que cada um execute suas movimentações sem atrapalhar o processo; e auxiliando no fluxo de informação. Em virtude desses ganhos, será possível reduzir os tempos de ciclo, entregando produtos de qualidade com agilidade, o que se torna vantagem competitiva, visto seu segmento de atuação.

\subsection{Avaliação das melhorias}

Com o intuito de validar a efetividade das melhorias propostas, técnicas de avaliação foram instituídas. Inicialmente, foi elaborado um formulário para que seja possível entender a perspectiva do consumidor diante dos produtos e serviços prestados (Quadro1).

Quadro 1- Check list de feedback

\begin{tabular}{|l|l|l|l|l|l|}
\hline \multicolumn{5}{|c|}{ CHECK LIST DE FEEDBACK COM O CLIENTE } \\
\hline \multicolumn{1}{|c|}{ PERGUNTA } & EXCELENTE & BOM & REGULAR & RUIM \\
\hline 1-0 que você acha do atendimento? & & & & \\
\hline 2-0 que você acha do tempo de entrega? & & & & \\
\hline 3-0 que você acha do produto? & & & & \\
\hline $\begin{array}{l}\text { 4-0 que você acha do serviço de } \\
\text { delivery? }\end{array}$ & & & & \\
\hline 5-O que acha dos preços dos produtos? & & & & \\
\hline $\begin{array}{l}\text { 6-O que você acha da aparência do } \\
\text { produto? }\end{array}$ & & & & \\
\hline SUGESTÕ̃ES: & & & & \\
\hline
\end{tabular}

Fonte: Os autores (2020) 
Com base nas informações coletadas a partir deste formulário e nos dados gerados pelas vendas, a empresa acompanhará seu desempenho a partir de indicadores, o que lhe permite desenvolver estratégias mais assertivas e direcionadas às suas maiores necessidades no momento (Quadro 2).

Quadro 2- Indicadores de desempenho

\begin{tabular}{|c|c|c|c|}
\hline Ind. & Elemento & Fator & Medidas \\
\hline 1 & $\begin{array}{l}\text { Vendas de cada } \\
\text { produto }\end{array}$ & $\begin{array}{l}\text { Vendas de cada } \\
\text { produto por período }\end{array}$ & $\begin{array}{c}\text { Vendas semanais de } \\
\text { cada produto }\end{array}$ \\
\hline 2 & $\begin{array}{c}\text { Tempo de entrega por } \\
\text { bairro }\end{array}$ & $\begin{array}{c}\text { Tempo de entrega por } \\
\text { bairro por período }\end{array}$ & $\begin{array}{l}\text { Tempo de entrega } \\
\text { diário por bairro. }\end{array}$ \\
\hline 3 & $\begin{array}{l}\text { Não conformidades } \\
\text { detectadas pelos } \\
\text { clientes }\end{array}$ & $\begin{array}{l}\text { Não conformidades } \\
\text { detectadas pelos } \\
\text { clientes por período }\end{array}$ & $\begin{array}{l}\text { Número de } \\
\text { reclamações por } \\
\text { semana }\end{array}$ \\
\hline
\end{tabular}

Fonte: Os autores (2020)

Logo, a proposição de indicadores tem como um dos objetivos mensurar as melhorias que foram sugeridas. Para este caso, não houve essa mensuração, uma vez que não foi realizada nenhuma análise com os indicadores. Porém, a medida que a empresa desejar implementá-los, saberá o caminho a seguir.

\section{Considerações finais}

Diante da acirrada competitividade, as organizações devem atuar de forma eficiente e eficaz, visando sempre obter maior desempenho organizacional. Logo, OSM proporciona através da aplicação de métodos e técnicas meios para que as organizações consigam este maior desempenho. Neste sentido, a pesquisa tem como objetivo analisar e aplicar as técnicas associadas ao conceito de OSM em uma Hamburgueria, localizada no Agreste Pernambucano, visando melhorar os processos por meio de técnicas que atuem para redução de perdas.

A partir da aplicação do questionário, foram identificadas as maiores dificuldades da organização. Com isso, foi realizada uma análise de Pareto seguida de um Diagrama de causa e efeito, a fim de conhecer as principais causas que de fato tem interferido no desempenho da organização. Estas causas alertaram sobre problemas nos materiais, mão de obra, processos e meio ambiente. A partir destas categorias, a empresa percebeu que precisaria corrigir falhas na comunicação, fornecer treinamentos para os funcionários, melhorar a disposição dos matérias, entre outros. 
Como resultado da análise do Diagrama de causa e efeito, foram lançadas como propostas de melhoria o mapeamento dos processos por meio do fluxograma e mudanças no layout atual da organização. Isso aconteceu para que atingisse as maiores categorias dos problemas que estavam causando a não conformidade dos produtos em relação aos pedidos que eram feitos.

Além da aplicação do questionário, a visita ao ambiente de trabalho foi extremamente útil para que fosse acompanhado de perto todo o processo produtivo e avaliado o fluxo de informações e pessoas, e a partir disso poder elaborar uma nova proposta de layout, na busca de minimizar os desperdícios, consequentemente tornar eficazes as operações.

Toda e qualquer mudança ou proposta sugerida esteve alinhada com a cultura da organização e precisa ser medida para que de fato se entenda sua efetividade. Para isso, um checklist de feedback dos clientes e um quadro de indicadores de desempenho foram apresentados para que o gestor entenda os caminhos que precisam trilhar a partir daquele momento e assim poder comparar a situação atual com a futura. Tais propostas alcançaram as diversas áreas da empresa e quando implantadas, trarão diferentes competências que levarão à organização um desempenho organizacional eficaz.

Desta forma, o trabalho permitiu compreender que independente do porte e tamanho da empresa, proporcionar a racionalização do trabalho através da definição do fluxo de informações, análise, criação e adaptação de formas alternativas para a realização do trabalho traz para as organizações um aumento significativo de sua competência e, ocasionando assim uma vantagem competitiva sustentável. 


\section{REFERÊNCIAS}

ALBUQUERQUE, Alan; ROCHA, Paulo. Sincronismo Organizacional. São Paulo: Saraiva. 2007.

ARAUJO, Luís Cesar G. de. Organização, sistemas e métodos e as tecnologias de gestão organizacional. 4. ed. São Paulo: Atlas, 2009.

ASSOCIATION OF BUSINESS PROCES MANAGEMENT PROFESSIONALS - ABPMP. BPM CBOK Guia para o Gerenciamento de Processos de Negócios - Corpo Comum de Conhecimento. $2^{\mathrm{a}}$ Ed., 2009.

ASSUNPÇÃO, Lucas Eggers; JACOBS, William. Estudo comparativo entre layouts sob a ótica da teoria das restrições com apoio de simulação de eventos discretos em empresa de alimentos. Revista Produção Online. Florianópolis, SC, v. 19, n. 1, p. 152-178, 2019.

BALDAM, R.; VALLE, R.; ROZENFELD, Henrique. Gerenciamento de processos de negócios BPM: Uma referência para implantação prática. 1. ed. Rio de Janeiro: Elsevier, 2014.

BROCKE, J. V.; ROSEMANN, M. Manual de BPM: gestão de processos de negócio. Porto Alegre: Bookman, 2013.

CRUZ, Tadeu. Sistemas, Organizações e Métodos. 3 ed. Revista, 2003.

CURY, Antônio. Organização e métodos: uma visão holística. São Paulo: Atlas S.A, 2012.

CURY, Antônio. Organização e métodos: uma visão holística. São Paulo: Atlas, 2000.

GAITHER, N.; FRAZIER, G. Administração da produção e operações. 8. ed. São Paulo: Pioneira, 2002.

GERMANO, Pedro Manuel Leal; GERMANO, Maria Izabel Simões. Sistema de gestão: Qualidade e se segurança dos alimentos. São Paulo: Manole, 2012.

GONÇALVES, J. E. L. As empresas são grandes coleções de processos. Revista de Administração de Empresas- RAE, v. 40, n. 1, p. 6-19, 2000.

KRAJEWSKI, L.; RITZMAN, L.; MALHOTRA, M. Administração de produção e operações. 8. ed. São Paulo: Pearson Prentice Hall, 2009.

OLIVEIRA, José Maria de; BITTENCOURT, Jairo Alano; MOREIRA, Simone Aparecida; CHAGAS, Paulo Cesar. A Representatividade das Técnicas de Osm para o Desenvolvimento das Organizações. 2011. Anais: VIII Simpósio de Excelência em Gestão e Tecnologia - SEGET. Disponível em: www.aedb.br/seget/arquivos/artigos11/60814769.pdf. Acesso em: 06 fevereiro de 2020.

PAIM, R.; CARDOSO, V.; CAULLIRAUX, H. Gestão de processos: pensar, agir e aprender. Porto Alegre: Bookman, 2009.

PIZZA, W. R. A metodologia Business Process Management (BPM) e sua importância para as organizações. Monografia apresentada no curso de Tecnologia em processamento de dados na Faculdade de Tecnologia de São Paulo-FATEC SP, 2012. Disponível em: http://www.fatecsp.br/dti/tcc/tcc00084.pdf. Acesso em: 06 de fevereiro de 2020.

ROCHA, Luiz Oswaldo Leal da. Organização e Métodos. São Paulo: Atlas, 1998.

SLACK, Nigel; CHAMBERS, Stuart; JOHNSTON, Robert. Administração da produção. 3. ed. São Paulo: Atlas, 2009.

SOUZA, Antonio Ediglei de; SOUSA, Giselly Viana; LOPES, Luma Louise Sousa. Os Desafios da Área de Osm na Atualidade. Revista FATENE, 2015. Disponível em: http://www.fatene.edu.br. Acesso em: 06 de fevereiro de 2020. 